\title{
An electrochemical sensor based on reduced graphene oxide/gold nanoparticles modified electrode for determination of iron in coastal waters
}

\author{
Yun Zhu ${ }^{a, b}$, Dawei Pan ${ }^{a, b, c, *}$, Xueping Hu ${ }^{a, b}$, Haitao Han ${ }^{a}$, Mingyue Lin ${ }^{a, b}$, \\ Chenchen Wang ${ }^{\mathrm{a}}$ \\ a Key Laboratory of Coastal Environmental Processes and Ecological Remediation, Yantai Institute of Coastal Zone Research (YIC), Chinese Academy of \\ Sciences (CAS), Shandong Provincial Key Laboratory of Coastal Environmental Processes, YICCAS, Yantai, Shandong 264003, PR China \\ ${ }^{\mathrm{b}}$ University of Chinese Academy of Sciences, Beijing 100049, PR China \\ ${ }^{\mathrm{c}}$ Department of Earth, Ocean and Ecological Sciences, School of Environmental Science, University of Liverpool, Liverpool L69 $3 G P$, UK
}

\section{A R T I C L E I N F O}

\section{Article history:}

Received 18 July 2016

Received in revised form

22 November 2016

Accepted 22 November 2016

Available online 23 November 2016

\section{Keywords:}

Reduced graphene oxide

Gold nanoparticles

Iron

Electrochemical reduction

Coastal waters

\begin{abstract}
A B S T R A C T
An electrochemical sensor based on reduced graphene oxide (rGO) and gold nanoparticles (AuNPs) modified electrode was utilized for determination of trace iron in coastal waters with the aid of the iron complexing ligand 2-(5-bromo-2-pyridylazo)-5-diethylaminophenol (5-Br-PADAP). 5-Br-PADAP reacted with iron in short chelating reaction time $(<3 \mathrm{~min})$. $\mathrm{rGO}$ as a support provided large specific surface area for AuNPs, which would facilitate the electrochemical reduction of Fe(III)-5-Br-PADAP. Under the optimized conditions, the response of $\mathrm{Fe}(\mathrm{III})$ at this resulting sensor was linear in the range of $30 \mathrm{nM}$ to $3 \mu \mathrm{M}$ with a detection limit of $3.5 \mathrm{nM}$. This sensor also had excellent reproducibility and repeatability. Additionally, the modified electrode had been successfully applied to the determination of Fe(III) in real coastal waters.
\end{abstract}

(C) 2016 Elsevier B.V. All rights reserved.

\section{Introduction}

Iron is one of the essential micronutrient elements for the organisms in the ecological system [1]. It is imperative in plant metabolism, electron transport of photosynthesis and respiration, chlorophyll synthesis, nitrate reduction, and detoxification of reactive oxygen species [2]. So the accurate quantitative determination of total dissolved iron in coastal waters is extremely important to be developed for the environment monitoring. The concentration of soluble iron in natural water is diverse in coastal water $\left(10^{-6}-10^{-9} \mathrm{M}\right)$, and ocean water $\left(10^{-9}-10^{-12} \mathrm{M}\right)[3]$. The coastal water has some properties such as salinization [4] and no permanently oxygenated condition [5]. Because the concentration of iron in coastal water is relatively lower, the accurate determination of iron concentrations in coastal water is one of the challeng-

\footnotetext{
* Corresponding author at: Key Laboratory of Coastal Environmental Processes and Ecological Remediation, Yantai Institute of Coastal Zone Research (YIC), Chinese Academy of Sciences (CAS), Shandong Provincial Key Laboratory of Coastal Environmental Processes, YICCAS, Yantai, Shandong 264003, PR China.

E-mail address: dwpan@yic.ac.cn (D. Pan).
}

ing problems in environmental analysis. Many techniques have been developed to determine iron such as spectrophotometry [6,7], atomic absorption spectrometry (AAS) [8,9], inductively coupled plasma-mass spectrometry (ICP-MS) [10] and fluorescence [11], etc. However, most of the methods need for expensive and bulky devices which restrict their use for in situ determination. Moreover, some methods suffer from serious matrix interferences.

Electrochemical method [12-14] has been identified as an extremely sensitive technique for iron determination due to its advantages of low cost, fast analysis speed, quick detection, portable instruments, high sensitivity and selectivity. Nowadays iron was always detected by using mercury electrode as working electrode $[15,16]$. Several complexing agents had been used to accumulate iron complexes on the electrode surface such as salicylaldoxime [17], 1-(2-piridylazo)-2-naphthol [18], 1-nitroso2-naphthol(NN) [19,20], 2-(2-thiazolylazo)-p-cresol(TAC) [21] and 2, 3-dihydroxynaphtalene (DHN) [22,23]. However, mercury electrode had some drawbacks including toxicity and difficulties in the handling [24] and the chelating reaction time was relatively longer. Chemically modified electrodes have been gradually developed for iron determination to avoid these disadvantages of mercury electrode. 
Nowadays, Nanomaterials [25-28] play an important role in analytical chemistry. Graphene [29] was found by Geim [30] in 2004. Many researchers pay more attention to it because of its high surface area, excellent conductivity, strong mechanical strength and high chemical stability. Gold nanomaterials [31,32] have the advantages of high catalytic activity, good biocompatibility and fast electron transfer rate [33]. Recently, some researchers showed that the deposited metal nanoparticles can improve the performance of the electrode. Graphene and gold nanocomposites have more excellent performance so they can be widely used in analysis field.

In this study, our working electrode was modified with rGO and AuNPs via one single step, which was similar to the reported literatures [34,35]. GO and $\mathrm{HAuCl}_{4}$ changed to rGO and AuNPs by electrochemical reduction at $-1.0 \mathrm{~V}$ for $400 \mathrm{~s}$. rGO might provide large specific surface area for AuNPs, which could accelerate the electron transfer. 5-Br-PADAP as the complexing ligand had the advantage of short chelating reaction time and $\mathrm{Fe}(\mathrm{III})-5-\mathrm{Br}-$ PADAP could be absorbed on the modified electrode [36]. The rGO/AuNPs modified electrode was easily fabricated and had excellent electrochemical properties. Experimental parameters such as the deposition time of $\mathrm{rGO} / \mathrm{AuNPs}$, the $\mathrm{pH}$ value of the acetate buffer, the accumulation potential and time, the concentration of 5-Br-PADAP and the time of chelating reaction were investigated in detail. The rGO/AuNPs modified electrode had the benefits of excellent selectivity, sensitivity and reproducibility for the determination of Fe(III). Additionally, the rGO/AuNPs modified electrode was also applied to the determination of $\mathrm{Fe}(\mathrm{III})$ in real coastal waters with satisfactory results.

\section{Experimental}

\subsection{Reagents}

All chemicals were of analytical reagent grade. Iron standard solutions were prepared from iron chloride (Sinopharm Chemical Reagent Co., Ltd., China.) in $0.1 \mathrm{M} \mathrm{HCl}$. GO was supplied by Nanjing Jcnano Technology Co. Ltd. $\mathrm{HAuCl}_{4} \cdot 4 \mathrm{H}_{2} \mathrm{O}$ was purchased from Sinopharm Chemical Reagent Co. Ltd. 5-Br-PADAP was purchased from Aladdin industrial corporation. Deionized water $(18.2 \mathrm{M} \Omega \mathrm{cm}$ specific resistance) obtained with a Pall Cascada laboratory water system was used throughout.

\subsection{Apparatus}

The morphologies of the rGO and AuNPs were characterized by scanning electron microscopy (SEM, Hitachi S-4800 microscope, Japan.). Electrochemical Work Station (CHI 660D, Shanghai CH Instruments, Shanghai, China) was utilized throughout all the electrochemical experiments. The rGO and AuNPs coated glassy carbon electrode ( $3 \mathrm{~mm}$ in diameter) served as a working electrode, an $\mathrm{Ag} / \mathrm{AgCl}$ (saturated $\mathrm{KCl}$ solution) was used as a reference electrode, and a platinum foil counter electrode was employed as an auxiliary electrode. All potentials were measured with respect to the $\mathrm{Ag} / \mathrm{AgCl}$ reference electrode.

\subsection{Preparation of the rGO/AuNPs modified electrode}

Prior to use, the GCE was polished using aqueous alumina slurry ( 0.3 and $0.05 \mu \mathrm{m}$ ), washed with deionized water thoroughly, and then ultrasonicated in deionized water for a while. The GCE electrode was immersed in $0.2 \mathrm{M}$ sodium sulfate solution containing $0.5 \mathrm{mg} / \mathrm{mL}$ GO and $1.0 \mathrm{mM}$ chlorauric acid to electrochemically electrodeposit rGO and AuNPs with constant potential at $-1.0 \mathrm{~V}$ for $400 \mathrm{~s}$ according to the literatures $[34,35,37,38]$. The obtained
rGO/AuNPs modified electrode was washed carefully with deionized water.

\subsection{Preparation of real coastal water samples}

Coastal river water samples were collected from Yuniao river (a local coastal river, which flows into the Huanghai Sea, Shandong province, China). Coastal sea water samples were collected from the Huanghai Sea (Shandong province, China). All the water samples were stored in acid-cleaned polyethylene bottles after filtration $(0.45 \mu \mathrm{m}$ membrane filters $)$ and kept at $4{ }^{\circ} \mathrm{C}$ until determination. The samples were digested in quartz tubes using a 500 W UV lamp (Metrohm MVA-UV 705, Switzerland). Voltammetric measurements were performed on diluted water samples to an appropriate concentration with the $0.1 \mathrm{M}$ acetate buffer ( $\mathrm{pH} 6.0$ ) supporting electrolyte.

\subsection{Electrochemical analysis procedure}

Unless otherwise stated, the experiments were performed in $0.1 \mathrm{M}$ acetate buffer ( $\mathrm{pH} 6.0$ ) supporting electrolyte containing $20 \mu \mathrm{M}$ 5-Br-PADAP. Firstly, Fe(III)-5-Br-PADAP complex was accumulated onto the surface of the modified electrode under a potential of $-0.1 \mathrm{~V}$ for $360 \mathrm{~s}$ with stirring. Then the stripping voltammetry was carried out from -0.40 to $-0.65 \mathrm{~V}$ by differential pulse voltammetry (DPV) using the following parameters: initial potential of $-0.40 \mathrm{~V}$, final potential of $-0.65 \mathrm{~V}$, amplitude of $0.05 \mathrm{~V}$, potential incremental of $0.004 \mathrm{~V}$, pulse width of $0.05 \mathrm{~s}$, pulse period of $0.5 \mathrm{~s}$ and quiet time of $2 \mathrm{~s}$.

\section{Results and discussion}

\subsection{Characterization of the rGO/AuNPs modified electrode}

The morphologies of the various modified electrodes were characterized by SEM. Fig. 1a shows the surface morphology of $\mathrm{GCE} / \mathrm{rGO}$, large flakes of rGO with slightly scrolled edges form was obtained. Fig. 1b-d show the surface morphologies of the rGO/AuNPs modified electrode at different magnifications. The successful attachment of the AuNPs on the rGO was obviously observed and the shape of AuNPs was spherical nanostructure with diameter in $20-40 \mathrm{~nm}$.

\subsection{Electrochemical responses of iron on the rGO/AuNPs modified electrode}

Fig. 2 shows the DPVs of the glassy carbon electrode, rGO/AuNPs, AuNPs and rGO modified electrode in $0.1 \mathrm{M}$ acetate buffer ( $\mathrm{pH}$ 6.0) with and without $20 \mu \mathrm{M}$ 5-Br-PADAP or $300 \mathrm{nM} \mathrm{Fe(III).} \mathrm{No}$ cathodic signal of $\mathrm{Fe}(\mathrm{III})$ was observed at the rGO/AuNPs electrode in $0.1 \mathrm{M}$ acetate buffer supporting electrolyte (curve a). In the absence of $\mathrm{Fe}(\mathrm{III})$, a cathodic peak attributed to the reduction of free 5-Br-PADAP was obtained at $-0.4 \mathrm{~V}$ (curve b). While two peaks at -0.4 and $-0.5 \mathrm{~V}$ were obtained in the presence of $\mathrm{Fe}(\mathrm{III})$ (curve c). The peak at $-0.5 \mathrm{~V}$ was attributed to the reduction of the $\mathrm{Fe}(\mathrm{III})-5-\mathrm{Br}-\mathrm{PADAP}$ complex. More importantly, the peak current of $\mathrm{Fe}$ (III)-5-Br-PADAP at rGO/AuNPs modified electrode is larger than that at AuNPs modified electrode (curve d).

Comparatively, DPVs of the glassy carbon electrode and rGO modified electrode in $0.1 \mathrm{M}$ acetate buffer ( $\mathrm{pH}$ 6.0) supporting electrolyte containing $20 \mu \mathrm{M}$ 5-Br-PADAP and $300 \mathrm{nM}$ Fe(III) were shown in Fig. 2b. From the curve $f$ and curve $g$, the rGO modified electrode can enhance electrochemical signals, the peaks of the $\mathrm{Fe}(\mathrm{III})-5-\mathrm{Br}-\mathrm{PADAP}$ and 5-Br-PADAP were not separated in glassy carbon electrode and rGO modified electrode. But they were separated in $\mathrm{rGO} /$ AuNPs modified electrode (curve c), which indicated 

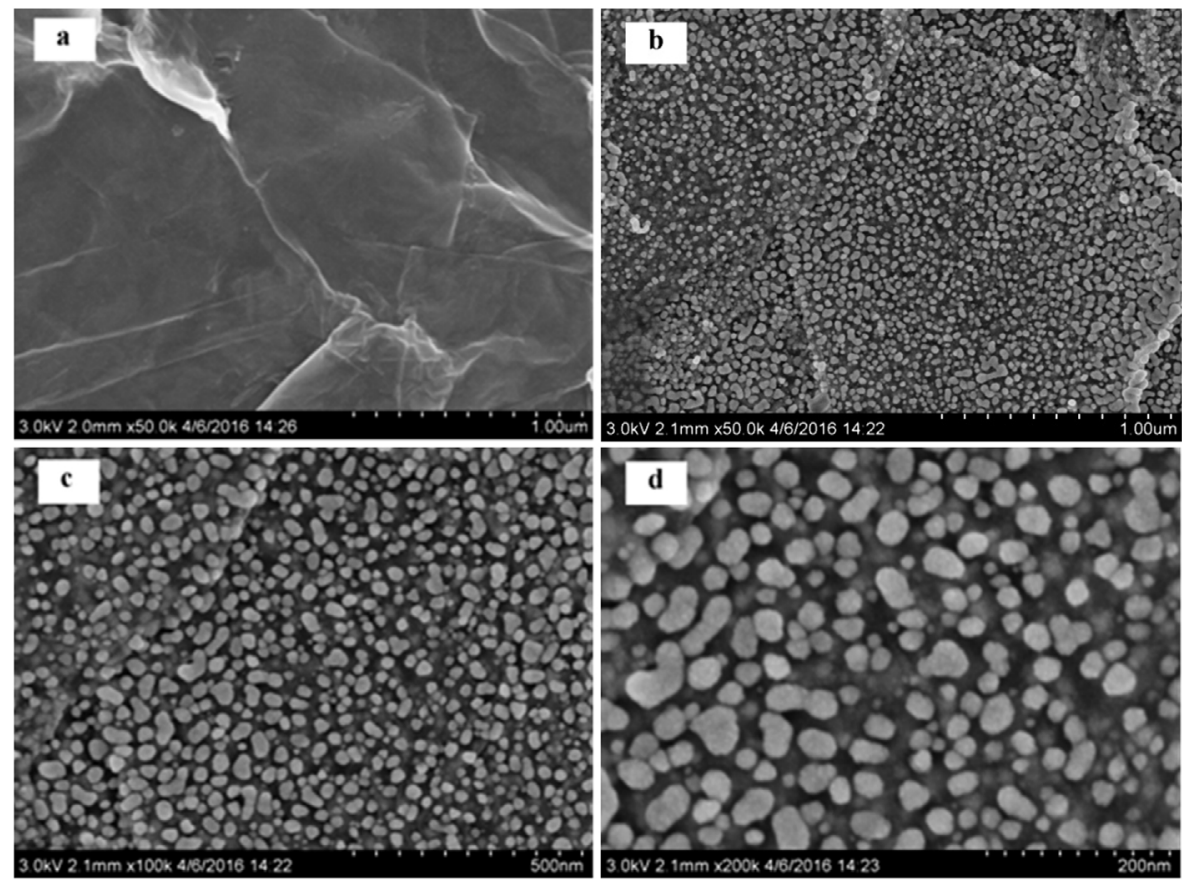

Fig. 1. SEM micrographs of the GCE/rGO (a), GCE/rGO/AuNPs (b, c and d).
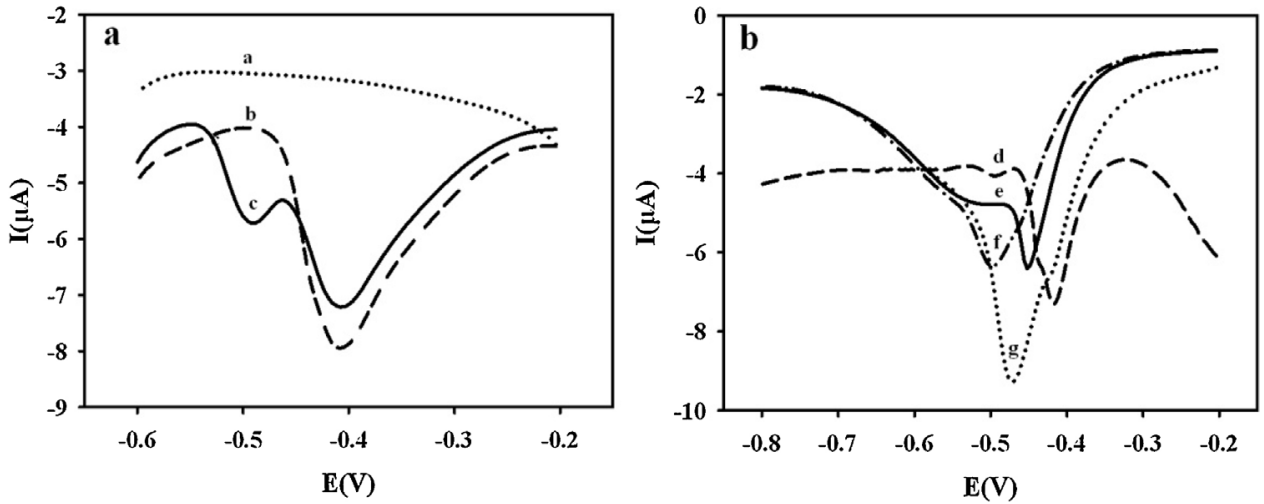

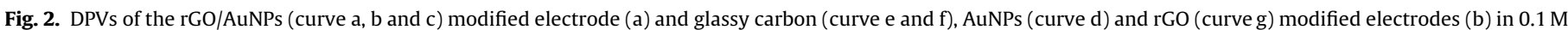
acetate buffer (pH 6.0) (curve a), containing $20 \mu \mathrm{M}$ 5-Br-PADAP (curve b and e) and $300 \mathrm{nM}$ Fe(III) (curve c, d, f and g).

the rGO/AuNPs modified electrode could be used to detect the $\mathrm{Fe}(\mathrm{III})$ with the help of 5-Br-PADAP.

\subsection{Optimization for iron measurement on the rGO/AuNPs modified electrode}

\subsubsection{Effect of the deposition time of the rGO/AuNPs at the GCE surface}

The deposition time of the rGO/AuNPs at the GCE surface was investigated with the time ranging from 60 to $500 \mathrm{~s}$. As shown in Fig. 3a, the peak current gradually decreased from 60 to $300 \mathrm{~s}$ and then increased from 300 to $400 \mathrm{~s}$ as well as decreased again. The maximum peak current of the complex was observed at the deposition time of $400 \mathrm{~s}$. Although the little amount of AuNPs was obtained at short time, the rare rGO was formed. After almost $300 \mathrm{~s}$ deposition, the rGO/AuNPs nanocomposite was obtained. Considering that the amount and size of AuNPs became larger and larger and the specific surface area might decrease with the increase of the deposition time. Deposition time of $400 \mathrm{~s}$ was considered as the optimum.

\subsubsection{Effect of $p H$ value of the acetate buffer}

Considering that the formation and stability of the $\mathrm{Fe}(\mathrm{III})-5-\mathrm{Br}-$ PADAP complex are strongly dependent on the $\mathrm{pH}$ value of solution. The effect of $\mathrm{pH}$ value of the acetate buffer was investigated at the $\mathrm{pH}$ value ranging from 4.0 to 7.0. As shown in Fig. 3b, the maximum peak current of the complex was observed at $\mathrm{pH}$ 6.0. The peak current was smaller at a lower $\mathrm{pH}$ value, which is probably due to the high background current caused by the hydrogen dissolving. Moreover, the peak current decreased with the $\mathrm{pH}$ value above 6.0 , which was probably due to the decomposition of the Fe(III)-5-Br-PADAP complex. The optimum $\mathrm{pH}$ value of the acetate buffer was chosen to be 6.0 .

\subsubsection{Effect of the accumulation potential}

The accumulation potential of $\mathrm{Fe}(\mathrm{III})-5-\mathrm{Br}-\mathrm{PADAP}$ at the modified electrode was investigated at the potential ranging from -0.4 to $0.1 \mathrm{~V}$. As shown in Fig. 3c, the maximum peak current of the complex was observed at the accumulation potential of $-0.1 \mathrm{~V}$, The peak current of the complex gradually increased from -0.4 to $-0.1 \mathrm{~V}$, which probably due to the positive charged complex being strongly adsorbed on the negative charged surface of the rGO/AuNPs mod- 


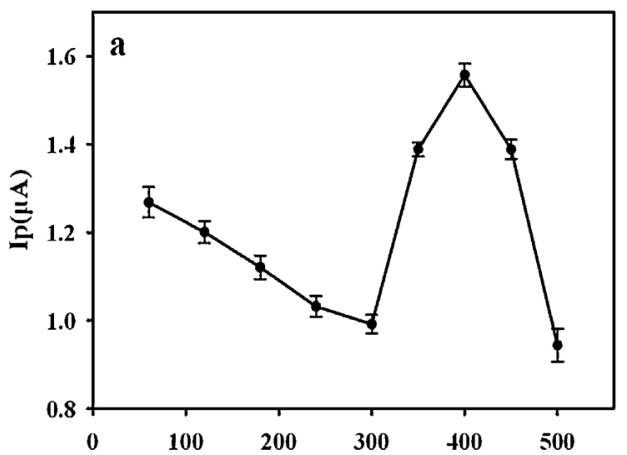

$t(s)$
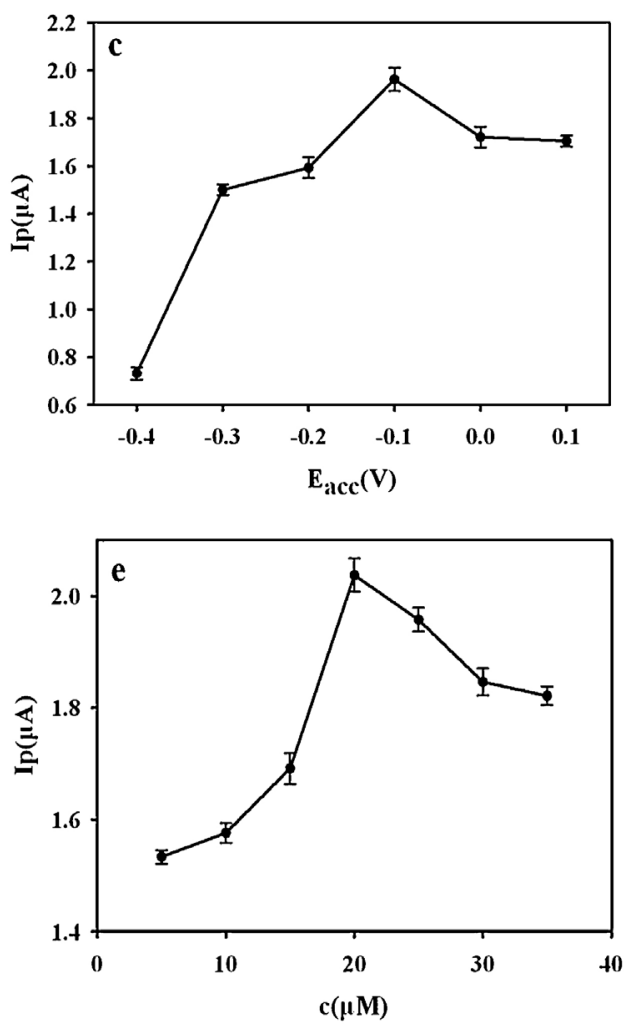
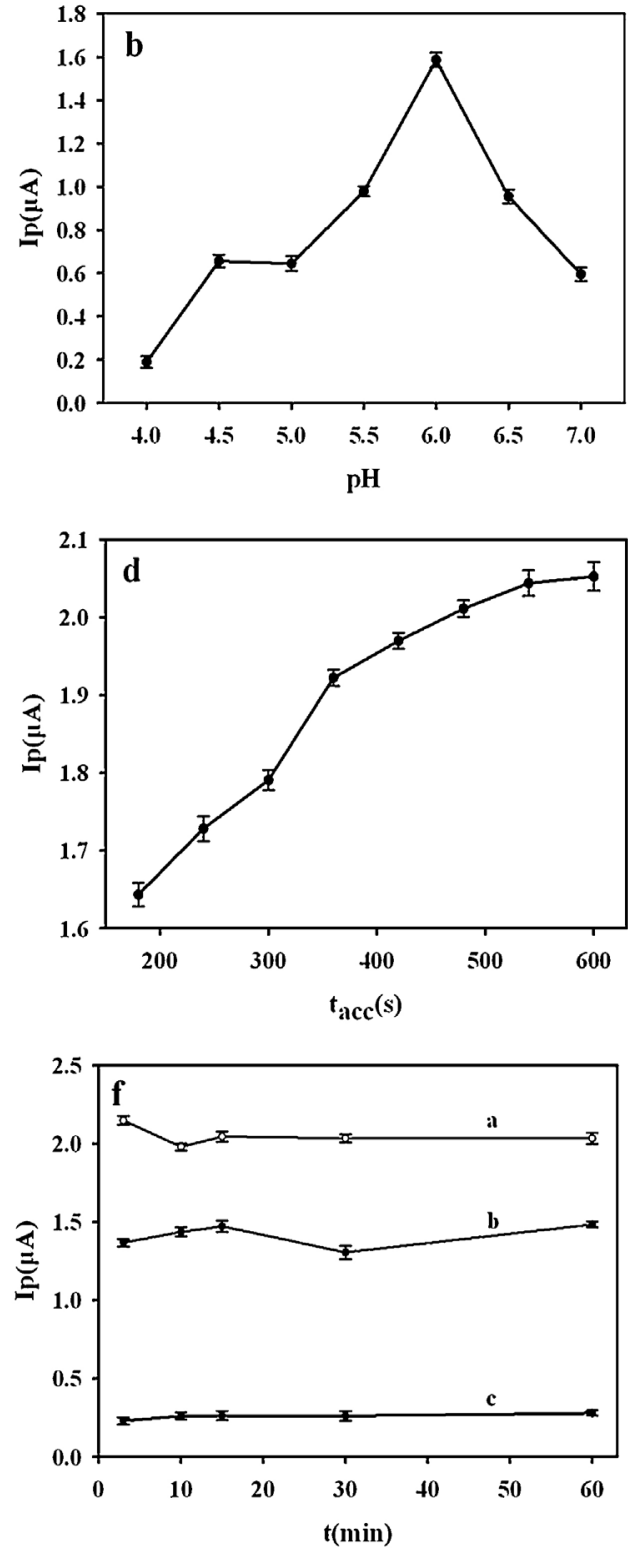

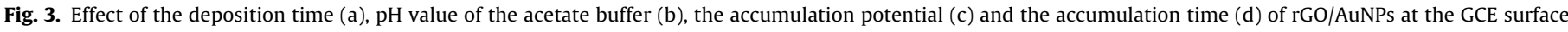

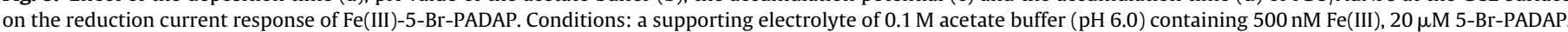

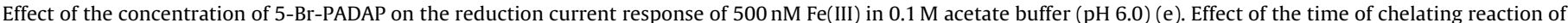
$\mathrm{Fe}(\mathrm{III})-5-\mathrm{Br}$-PADAP. Conditions: a supporting electrolyte of $0.1 \mathrm{M}$ acetate buffer (pH 6.0) containing 500 nM Fe(III), 20, 10, $1 \mu \mathrm{M}$ 5-Br-PADAP (curve a, b and c) (f).

ified electrode. The maximum current was observed at a potential of $-0.1 \mathrm{~V}$. However, the peak current decreased with increasing potential from -0.1 to $0.1 \mathrm{~V}$ because enough $\mathrm{Fe}(\mathrm{III})-5-\mathrm{Br}-\mathrm{PADAP}$ complex were not adsorbed at the modified electrode. Thus, $-0.1 \mathrm{~V}$ was considered as the optimal accumulation potential.

\subsubsection{Effect of accumulation time}

The effect of accumulation time on the peak current was studied ranging from 180 to $600 \mathrm{~s}$, As shown in Fig. 3d, the peak current of the Fe(III)-5-Br-PADAP complex increased rapidly as the accumulation time increased from $180 \mathrm{~s}$ to 360 s, and then tended to increase slowly. Considering the time of analysis and energy consumption problem, $360 \mathrm{~s}$ was considered as the optimal accumulation time.

\subsubsection{Effect of the concentration of 5-Br-PADAP}

The effect of the concentration of 5-Br-PADAP was investigated at the concentration ranging from 5 to $35 \mu \mathrm{M}$ in $0.1 \mathrm{M}$ acetate buffer ( $\mathrm{pH}$ 6.0) containing $500 \mathrm{nM}$ Fe(III). As shown in Fig. 3e, the maximum peak current of the complex was observed at the concentration of $20 \mu \mathrm{M}$, the peak current was smaller at a lower concentration value, which is probably due to the lower concentration were too dilute to have enough deposition points. However, the peak current decreased with increasing concentration from 20 to $35 \mu \mathrm{M}$ because the higher concentration of 5-Br-PADAP can be competitive with $\mathrm{Fe}(\mathrm{III})-5-\mathrm{Br}-\mathrm{PADAP}$. Thus, the optimum 5-BrPADAP concentration was chosen as $20 \mu \mathrm{M}$.

\subsubsection{Effect of the time of chelating reaction}

The chelating reaction between $\mathrm{Fe}(\mathrm{III})$ and 5-Br-PADAP was very quick. As shown in Fig. $3 \mathrm{f}$, the effect of the time of chelating reaction was investigated with the time ranging from 3 to $60 \mathrm{~min}$ in $0.1 \mathrm{M}$ acetate buffer ( $\mathrm{pH} 6.0$ ) containing $500 \mathrm{nM} \mathrm{Fe}(\mathrm{III})$ and 20, 10 and $1 \mu \mathrm{M}$ 5-Br-PADAP (curve a, b and c), respectively. The peak current of the Fe(III)-5-Br-PADAP complex was almost no matter 
Table 1

Comparison of the electrochemical methods with other analytical methods for iron determination.

\begin{tabular}{|c|c|c|c|c|c|}
\hline Methods & Electrode & Agents & Linear range $(\mathrm{nM})$ & LOD (nM) & Reference \\
\hline $\begin{array}{l}\text { DLLME }^{\text {/ }} \\
\text { UV-vis }\end{array}$ & No & 5-Br-PADAP & $90-7000$ & 27 & {$[6]$} \\
\hline ICP-MS & No & Nitrilotriacetic acid chelating resin & $0.02-0.07$ & 0.02 & {$[10]$} \\
\hline Fluorescence & No & RHA $^{\mathrm{c}}$ & $500-5000$ & 300 & [11] \\
\hline $\mathrm{CSV}^{\mathrm{d}}$ & $\mathrm{HMDE}^{\mathrm{e}}$ & $\mathrm{NN}^{\mathrm{f}}$ & Not mentioned & 0.08 & [20] \\
\hline CSV & HMDE & $\mathrm{DHN}^{g}$ & Not mentioned & 0.005 & [22] \\
\hline CSV & Mercury coated, gold, micro-wire electrode & DHN & Not mentioned & 0.1 & [23] \\
\hline CSV & HMDE & 5-Br-PADAP & $0.25-100$ & Not mentioned & [36] \\
\hline SWV & IL-rGO/AuNDs/Nafion & No & $300-100000$ & 35 & {$[13]$} \\
\hline DPV & rGO/AuNPs & 5-Br-PADAP & $30-3000$ & 3.5 & This work \\
\hline
\end{tabular}

a Dispersive liquid-liquid microextraction.

b 2-(5-bromo-2-pyridylazo)-5-diethylaminophenol.

c Rhodamine amide.

d Cathodic stripping voltammetry.

e Hanging mercury drop electrode.

f 1-nitroso-2-naphthol.

g 2,3-dihydroxynaphthalene.

Table 2

Comparison of this method and AAS for determination of Fe(III) in real water samples.

\begin{tabular}{|c|c|c|c|c|}
\hline Real samples & $\mathrm{Fe}(\mathrm{III})$ added (nM) & Detected by this method (nM) & Detected by AAS (nM) & Recovery (\%) \\
\hline Coastal river water 1 & - & $179 \pm 4.2$ & 178 & - \\
\hline Coastal river water 2 & - & $60.7 \pm 3.2$ & 62.5 & - \\
\hline \multirow[t]{3}{*}{ Coastal sea water } & 0 & - & - & - \\
\hline & 50 & $49.1 \pm 2.7$ & - & 98.2 \\
\hline & 100 & $97.3 \pm 3.9$ & - & 97.3 \\
\hline
\end{tabular}

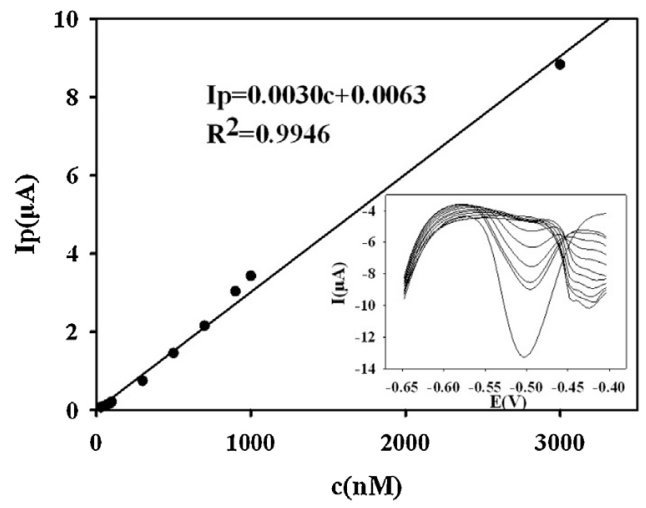

Fig. 4. Calibration curve of $\mathrm{Fe}(\mathrm{III})$ at the $\mathrm{rGO} /$ AuNPs modified electrode, where the concentrations of $\mathrm{Fe}(\mathrm{III})$ are from $30 \mathrm{nM}$ to $3 \mu \mathrm{M}$ in $0.1 \mathrm{M}$ acetate buffer ( $\mathrm{pH} 6.0$ ) containing $20 \mu \mathrm{M}$ 5-Br-PADAP. Inset is the voltammetric responses of $\mathrm{Fe}(\mathrm{III})$.

the chelating reaction time was 3 or 60 min. These imply that $5-\mathrm{Br}-$ PADAP reacted quickly with iron and got matured in short reaction time (<3 min). So, using 5-Br-PADAP might effectively shorten the testing time.

\subsection{Calibration curve}

The calibration curve of the Fe(III) determination was derived from the DPVs obtained at the rGO/AuNPs modified electrode under the optimum conditions mentioned above (Fig. 4). The peak current was linear with the concentration of $\mathrm{Fe}(\mathrm{III})$ ranging from $30 \mathrm{nM}$ to $3 \mu \mathrm{M}$. The equation for linear regression was $I_{p}=0.0030 \mathrm{c}+0.0063$ $\left(\mathrm{R}^{2}=0.9946\right)$. The sensitivity and detection limit of the rGO/AuNPs modified electrode for $\mathrm{Fe}(\mathrm{III})$ determination were $3 \mathrm{nAnM}^{-1}$ and $3.5 \mathrm{nM}(\mathrm{s} / \mathrm{n}=3)$, respectively. Additionally, comparisons about iron determination by electrochemical methods and other analytical methods were shown in Table 1. Compared with other electrodes, the rGO/AuNPs modified electrode may be a good choice for iron determination with higher sensitivity, lower detection limit and wider linear range.

\subsection{Reproducibility, repeatability and selectivity}

The reproducibility of the rGO/AuNPs modified electrode was investigated in $300,500,700 \mathrm{nM}$ Fe(III) by six independently modified electrodes prepared with the same method and the relative standard deviation (RSD) was $5.7 \%, 5.4 \%, 4.7 \%$, respectively. The repeatability of the developed method was also evaluated by detecting 300, 500, $700 \mathrm{nM} \mathrm{Fe}(\mathrm{III})$ at the same electrode for six measurements and the RSD was 3.6\%, 3.9\%, 3.5\%, respectively. Hence, the rGO/AuNPs modified electrode showed good reproducibility and repeatability. If the modified electrode was stored in air condition and tested by two determinations for both 300 and $500 \mathrm{nM}$ $\mathrm{Fe}(\mathrm{III})$ in each day, the response current had no obvious decrease during six days. But it would retain only $70 \%$ of its initial response from the seventh day.

To investigate the effects of possible interfering species for the iron determination, various foreign species were added into $0.1 \mathrm{M}$ acetate buffer ( $\mathrm{pH}$ 6.0) containing $500 \mathrm{nM} \mathrm{Fe}(\mathrm{III}) .200$-fold $\mathrm{Ca}^{2+}, 50$ fold $\mathrm{Mg}^{2+}, \mathrm{Mn}^{2+}$ and $\mathrm{Al}^{3+}, 30$-fold $\mathrm{Cd}^{2+}$ and $\mathrm{Cr}^{3+}, 10$-fold $\mathrm{Zn}^{2+}, \mathrm{Pb}^{2+}$ and $\mathrm{Cu}^{2+}$ did not affect the determination of $\mathrm{Fe}(\mathrm{III})(<5 \%$ of response current change). We also investigated the effects of organic species, such as humic substances and catechol. The results showed that 10fold humic substances did not affect the determination of Fe(III), but 5 -fold catechol would decrease the peak current, because catechol was one of the common chelators of iron. However, after the UV digestion, the peak currents returned to be normal, because UV digestion can destroy the organic substances.

\subsection{Practical application}

To evaluate the practical application of the rGO/AuNPs modified electrode, the modified electrode was used for the total dissolved iron determination in coastal water samples. Coastal river water 1 was diluted 10 times then added to $0.1 \mathrm{M}$ acetate buffer $(\mathrm{pH} 6.0$ ) for 


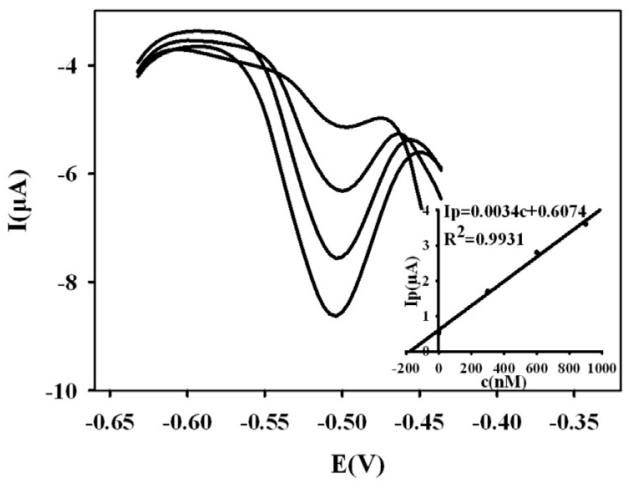

Fig. 5. Voltammetric responses of $\mathrm{Fe}(\mathrm{III})$ in coastal river water 1 by the standard addition method. The concentrations of the addition of Fe(III) are $0,300,600,900 \mathrm{nM}$ (from top to bottom), respectively. Inset is the fitted curve for Fe(III) determination.

detection by using the standard addition method under the optimal conditions. The adsorptive cathodic stripping curves of the coastal river water 1 were shown in Fig. 5 and the linear regression was shown in the inset of Fig. 5. The concentration of Fe(III) was calculated to be $179 \mathrm{nM}$ which was in agreement with the value detected by AAS (178 nM). Besides, the concentrations of Fe(III) in other samples were determined by our proposed method and AAS and the corresponding results were displayed in Table 2 . The results indicated that our proposed sensor was reliable and suitable for the determination of $\mathrm{Fe}(\mathrm{III})$ in waters from the coastal zone area.

\section{Conclusions}

In summary, a novel and effective rGO/AuNPs coated GCE was fabricated with 5-Br-PADAP as complexing agents for sensitive determination of $\mathrm{Fe}(\mathrm{III})$ in real coastal water samples. Compared to other complexing agents, 5-Br-PADAP has the advantage of short chelating reaction time. Moreover, the modified electrode has several advantages such as easy fabrication, excellent reproducibility, repeatability and selectivity. The fabricated electrode will be of great benefit to determine iron in waters from the coastal zone area.

\section{Acknowledgments}

This work was financially supported by the National Natural Science Foundation of China (41276093), the Youth Innovation Promotion Association (2011170), the Outstanding Young Scientists Program and the Equipment Development Project of Chinese Academy of Sciences (YZ201558).

\section{References}

[1] F.M.M. Morel, N.M. Price, The biogeochemical cycles of trace metals in the oceans, Science 300 (2003) 944-947.

[2] W.G. Sunda, S.A. Huntsman, Iron uptake and growth limitation in oceanic and coastal phytoplankton, Mar. Chem. 50 (1995) 189-206.

[3] M. Lu, N.V. Rees, A.S. Kabakaev, R.G. Compton, Determination of iron: electrochemical methods, Electroanalysis (2012) 1693-1702.

[4] R.-H. Kim, J.-H. Kim, J.-S. Ryu, H.-W. Chang, Salinization properties of a shallow groundwater in a coastal reclaimed area, Yeonggwang, Korea, Environ. Geol. 49 (2006) 1180-1194.

[5] A. BARATS, D. AMOUROUX, C. PÉCHEYRAN, L. CHAUVAUD, O.F.X. DONARD, High-Frequency archives of manganese inputs to coastal waters (Bay of seine, France) resolved by the LA-ICP-MS analysis of calcitic growth layers along scallop shells (Pecten maximus), Environ. Sci. Technol. 42 (2008) 86-92.

[6] B. Peng, Y. Shen, Z. Gao, M. Zhou, Y. Ma, S. Zhao, Determination of total iron in water and foods by dispersive liquid-liquid microextraction coupled with microvolume UV-vis spectrophotometry, Food Chem. 176 (2015) 288-293.

[7] W. Ruengsitagoon, Reverse flow injection spectrophotometric determination of iron(III) using chlortetracycline reagent, Talanta 74 (2008) 1236-1241.
[8] D.J. Leao, M.M.S. Junior, G.C. Brandao, S.L.C. Ferreira, Simultaneous determination of cadmium, iron and tin in canned foods using high-resolution continuum source graphite furnace atomic absorption spectrometry, Talanta 153 (2016) 45-50.

[9] P. Pohl, I. Sergiel, Direct determination of the total concentrations of copper, iron and manganese and their fractionation forms in freshly ripened honeys by means of flame atomic absorption spectrometry, Microchim. Acta. 168 (2009) 9-15

[10] J.d. Jong, V. Schoemann, D. Lannuzel, J.-L. Tison, N. Mattielli, High-accuracy determination of iron in seawater by isotope dilution multiple collector inductively coupled plasma mass spectrometry (ID-MC-ICP-MS) using nitrilotriacetic acid chelating resin for pre-concentration and matrix separation, Anal. Chim. Acta 623 (2008) 126-139.

[11] Y. Du, M. Chen, Y. Zhang, F. Luo, C. He, M. Li, X. Chen, Determination of iron(III) based on the fluorescence quenching of rhodamine B derivative, Talanta 106 (2013) 261-265

[12] D.I. Anguiano, M.G. García, C. Ruíz, J. Torres, I. Alonso-Lemus, L. Alvarez-Contreras, Y. Verde-Gómez, E. Bustos, Electrochemical detection of iron in a lixiviant solution of polluted soil using a modified glassy carbon electrode, Int. J. Electrochem. 2012 (2012) 1-6.

[13] F. Li, D. Pan, M. Lin, H. Han, X. Hu, Q. Kang, Electrochemical determination of iron in coastal waters based on ionic liquid-reduced graphene oxide supported gold nanodendrites, Electrochim. Acta 176 (2015) 548-554.

[14] X. Hu, D. Pan, M. Lin, H. Han, F. Li, Graphene oxide-assisted synthesis of bismuth nanosheets for catalytic stripping voltammetric determination of iron in coastal waters, Microchim. Acta 183 (2015) 855-861.

[15] H. Obata, C.M.G. v.d. Berg, Determination of picomolar levels of iron in seawater using catalytic cathodic stripping voltammetry, Anal. Chem. 73 (2001) 2522-2528.

[16] C.M.G. v.d. Berg, Chemical speciation of iron in seawater by cathodic stripping voltammetry with dihydroxynaphthalene, Anal. Chem. 78 (2006) 156-163.

[17] E.L. Rue, K.W. Bruland, Complexation of iron(III) by natural organic ligands in the Central North Pacific as determined by a new competitive ligand equilibration/adsorptive cathodic stripping voltammetric method, Mar. Chem. 50 (1995) 117-138.

[18] R. Segura, M.I. Toral, V. Arancibia, Determination of iron in water samples by adsorptive stripping voltammetry with a bismuth film electrode in the presence of 1-(2-piridylazo)-2-naphthol, Talanta 75 (2008) 973-977.

[19] T. Nagai, A. Imai, K. Matsushige, K. Yokoi, T. Fukushima, Voltammetric determination of dissolved iron and its speciation in freshwater, Limnology 5 (2004) 87-94.

[20] A.P. Aldrich, C.M. v.d. Berg, Determination of iron and its redox speciation in seawater using catalytic cathodic stripping voltammetry, Electroanalysis 10 (1998) 369-373.

[21] P.L. Croot, M. Johansson, Determination of iron speciation by cathodic stripping voltammetry in seawater using the competing ligand 2-(2-thiazolylazo)-p-cresol (TAC), Electroanalysis 12 (2000) 565-576.

[22] L.M. Laglera, J. Santos-Echeandia, S. Caprara, D. Monticelli, Quantification of iron in seawater at the low picomolar range based on optimization of bromate/ammonia/dihydroxynaphtalene system by catalytic adsorptive cathodic stripping voltammetry, Anal. Chem. 85 (2013) 2486-2492.

[23] J. Gun, P. Salaun, C.M. van den Berg, Advantages of using a mercury coated micro-wire, electrode in adsorptive cathodic stripping voltammetry, Anal. Chim. Acta 571 (2006) 86-92.

[24] J. Wang, Stripping analysis at bismuth electrodes: a review, Electroanalysis 17 (2005) 1341-1346.

[25] Y. Lan, H. Luo, X. Ren, Y. Wang, Y. Liu, Anodic stripping voltammetric determination of arsenic(III) using a glassy carbon electrode modified with gold-palladium bimetallic nanoparticles, Microchim. Acta 178 (2012) 153-161.

[26] L. Laffont, T. Hezard, P. Gros, L.E. Heimburger, J.E. Sonke, P. Behra, D. Evrard, Mercury(II) trace detection by a gold nanoparticle-modified glassy carbon electrode using square-wave anodic stripping voltammetry including a chloride desorption step, Talanta 141 (2015) 26-32.

[27] S.J. Cloake, H.S. Toh, P.T. Lee, C. Salter, C. Johnston, R.G. Compton, Anodic stripping voltammetry of silver nanoparticles: aggregation leads to incomplete stripping, ChemistryOpen 4 (2015) 22-26.

[28] J. Gong, T. Zhou, D. Song, L. Zhang, Monodispersed Au nanoparticles decorated graphene as an enhanced sensing platform for ultrasensitive stripping voltammetric detection of mercury(II), Sens. Actuators B 150 (2010) 491-497.

[29] P.M. Lee, Z. Chen, L. Li, E. Liu, Reduced graphene oxide decorated with tin nanoparticles through electrodeposition for simultaneous determination of trace heavy metals, Electrochim. Acta 174 (2015) 207-214.

[30] K.S. Novoselov, A.K. Geim, S.V. Morozov, Y.Z.D. Jiang, S.V. Dubonos, I.V. Grigorieva, A.A. Firsov, Electric field effect in atomically thin carbon films, Science 306 (2004) 666-669.

[31] Y. An, X. Jiang, W. Bi, H. Chen, L. Jin, S. Zhang, C. Wang, W. Zhang, Sensitive electrochemical immunosensor for alpha-synuclein based on dual signal amplification using PAMAM dendrimer-encapsulated Au and enhanced gold nanoparticle labels, Biosens. Bioelectron. 32 (2012) 224-230.

[32] Y. Zhao, L. Fan, J. Ren, B. Hong, Gold nanoclusters electrodeposited on multi-walled carbon nanotubes: enhanced electrocatalytic activity of hemoglobin, J. Solid State Electrochem. 18 (2014) 1099-1109.

[33] D. Marie-Christine, A. Didier, Gold nanoparticles: assembly, supramolecular chemistry, quantum-size-related properties, and applications toward biology, catalysis, and nanotechnology, Chem. Rev. 104 (2004) 293-346. 
[34] Y.G. Zhou, J.J. Chen, F.B. Wang, Z.H. Sheng, X.H. Xia, A facile approach to the synthesis of highly electroactive Pt nanoparticles on graphene as an anode catalyst for direct methanol fuel cells, Chem. Commun. 46 (2010) 5951-5953.

[35] L. Zaijun, S. Xiulan, X. Oianfang, L. Ruiyi, F. Yinjun, Y. Shuping, L. Junkang Green and controllable strategy to fabricate well-dispersed graphene-gold nanocomposite film as sensing materials for the detection of hydroquinone and resorcinol with electrodeposition, Electrochim. Acta 85 (2012) 42-48.

[36] J. Zhao, W. Jin, A study on the adsorption voltammetry of the iron(III)-2-(5'-bromo-2'-pyridylazo) -5-diethylaminophenol system. Electroanal. Chem. 267 (1989) 271-278.

[37] Z. Wang, X. Zhou, J. Zhang, F. Boey, H. Zhang, Direct electrochemical reduction of single-Layer graphene oxide and subsequent functionalization with glucose oxidase, J. Phys. Chem. C 113 (2009) 14071-14075.

[38] L. Chen, Y. Tang, K. Wang, C. Liu, S. Luo, Direct electrodeposition of reduced graphene oxide on glassy carbon electrode and its electrochemical application, Electrochem. Commun. 13 (2011) 133-137.

\section{Biographies}

Yun Zhu earned the BS degree of applied chemistry in 2014 at Yantai University. She is currently a master's degree student at Yantai Institute of Coastal Zone Research, Chinese Academy of Sciences. Her scientific interest includes electrochemical sensors and environmental analysis.
Dawei Pan is currently a professor at Yantai Institute of Coastal Zone Research Chinese Academy of Sciences. He received the Ph.D. degree in 2007 at Hunan University. His research interests focus on electrochemical sensor system's research and integration, electroanalysis of coastal environment's pollutants and nutrients, and interface electrochemistry.

Xueping Hu earned the BS degree in 2013 at Linyi University. She is currently a Ph.D. student at Yantai Institute of Coastal Zone Research, Chinese Academy of Sciences. Now she is engaged in synthesis of novel bismuth nanomaterials and environmental analysis.

Haitao Han is currently a research assistant at Yantai Institute of Coastal Zone Research, Chinese Academy of Sciences. He earned his master degree in 2014 at Yantai University. His research interests are in the area of synthesis of novel nanocomposites, electrochemical sensors and environmental analysis.

Mingyue Lin earned the BS degree in 2012 at Nanjing University of Information Science \& Technology. She is currently a Ph.D. student at Yantai Institute of Coastal Zone Research, Chinese Academy of Sciences. Her scientific interest includes electrochemical sensors, analysis of environmental pollutants and nutrients.

Chenchen Wang is currently a research assistant at Yantai Institute of Coastal Zone Research, Chinese Academy of Sciences. She earned her master degree in 2015 at Southeast University. Her research interests focus on the determination of heavy metals in intertidal sediments and coastal waters. 